EDITORIAL

\title{
The National Service Framework: six years on
}

\section{Has the National Service Framework for coronary heart disease resulted in the improvements in cardiac services it promised when first published six years ago?}

$\mathrm{T}$ he National Service Framework (NSF) for coronary heart disease (CHD) was published in March 2000. ${ }^{1}$ Mr Alan Milburn, the then Secretary of State for Health, introduced it as a blueprint for tackling heart disease, accepting in his foreword to the document that the parts of the National Health Service dealing with heart disease had suffered decades of neglect. He finished his introduction with the words: "This Framework will transform the prevention, diagnosis and treatment of coronary heart disease. It will help professionals to give better, fairer and faster care everywhere, to everyone who needs it. We want a service that is amongst the best in the world. Our people deserve nothing less." Unfortunately this was only relevant to people living in England, not the rest of the UK.

The NSF was greeted with much critical acclaim and enthusiasm, although some felt it was a second rate pamphlet stating it was a handbook for managers, not clinicians, and did not include calculations of funding requirements. ${ }^{2}$ Sir George Alberti, the co-chairman of the NSF, pointed out in his response that the NSF was a blueprint for all health professionals, not just for cardiologists, and that it should serve to counter both the ignorance and incompetence that existed.

The NSF was published in seven chapters and 12 national standards spanning the reduction of heart disease in the population, prevention of coronary disease in high risk patients, acute coronary syndromes, stable angina, revascularisation, heart failure, and rehabilitation. In March 2005 an additional chapter on arrhythmias and sudden cardiac death was added. ${ }^{3}$

The NSF is a 10 year programme. Six years have passed since its publication. A third report on progress on implementation was published in March 2005. ${ }^{4}$ Has the NSF resulted in the improvements in cardiac services it promised? The national clinical director for heart disease has stated that the achievements of a relatively bland document has been to rekindle the clinical spirit. ${ }^{5}$ His enthusiasm and that of the cardiological community has resulted in a welcome and badly needed expansion and development of cardiac services in England, although these still lag far behind other European countries in some areas.

\section{POSITIVE ACHIEVEMENTS}

The immediate treatment of heart attacks is one example. There is now an established

Heart 2006;92:291-292. doi: 10.1136/hrt.2005.066043

countrywide prehospital thrombolysis service. Twenty eight of 31 ambulance trusts now provide thrombolysis delivered by paramedics before hospital admission. Over 2500 patients have been treated in the last two years.

Another major achievement has been the Myocardial Infarction National Audit Project (MINAP) running in parallel with the NSF and recently publishing its fourth report. ${ }^{6}$ Two hundred and eight hospitals in England and 18 in Wales now contribute data to this highly successful audit project. In-hospital thrombolysis has become much more efficient with many hospitals now using triage nurses in the accident and emergency department. Door to needle time of 30 minutes or less is now achieved in $86 \%$ of patients and 60 minute call to needle time in $55 \%$.

Six hundred and eighty automatic external defibrillators (AEDs) have been installed in 110 public places around the country. Over 6000 people have been trained in their use and 61 lives have definitely been saved in this way. Seventy six per cent of category A ambulance calls are now answered in eight minutes, although there have been uncertainties in the calculations as to when the clock is switched on.

Coronary angioplasty is also a rapidly expanding service in the UK. In 1999, the year before the NSF was published, 494 angioplasty procedures were performed per million of the population (British Cardiovascular Intervention Society (BCIS) registry). In 2003 this figure had risen to 894 /million: past the target of $750 /$ million set in the NSF but short of the 1000/million felt to be necessary in many areas. In this period the number of centres performing coronary intervention has increased from 63 to 73. Angioplasty in selected district general hospitals is successfully increasing the number of procedures performed.

The cardiac workforce has improved. In 1999 there were 467 cardiologists in England, and by March 2004 this had risen to 692: an increase of $48 \%$ in less than five years. There should be no single handed cardiologists now. There was a $19 \%$ increase in cardiac surgeons (up to 217) by the end of 2004, but the rapid increase in annual coronary intervention procedures, and the plateau of coronary bypass operations over the last four years, has cast doubt on the need for more cardiac surgeons. The NSF has undoubtedly stimulated action on waiting lists for cardiac

Abbreviations: AED, automatic external defibrillators; BCIS, British Cardiovascular Intervention Society; CHD, coronary heart disease; MINAP, Myocardial Infarction National Audit Project; NSF, National Service Framework; $\mathrm{PCl}$, percutaneous coronary intervention 
surgery which have fallen dramatically. Five years ago many patients were waiting over two years for coronary artery bypass surgery. The maximum waiting time for most units is now three months.

Much of the success of the NSF has been in the development of an infrastructure to coordinate and organise the patient pathway. The primary care collaborative, the CHD collaborative national programme, the establishment of CHD networks, and the development of rapid access chest pain clinics throughout the country have all made a considerable difference to speeding up access to high quality cardiac care.

\section{DIRECT IMPROVEMENTS OR JUST PRE-EXISTING TRENDS?}

The question remains: how much of all these improvements were the result of the NSF initiative and how much were merely continuations of pre-existing trends? Graham and his colleagues $^{7}$ contribute a valuable answer to this question in this issue of Heart with a retrospective study on patients with acute coronary syndromes admitted to two coronary care units in East London. Their findings suggest that the NSF contributed to a reduction in mortality due to a highly significant reduction in Q wave myocardial infarction and left ventricular failure. This was associated with an increase in thrombolysis rates, decreased time to thrombolysis, and increased early revascularisation. Prescription rates for $\beta$ blockade or statin use, however, were not influenced by the NSF publication.

These data are supported by the BCIS registry which shows that the number of percutaneous coronary intervention (PCI) procedures performed was rising year by year before the NSF publication, but the rate of rise seems to have accelerated since 2000 .

Statin expenditure was rising steadily before the NSF publication and continues to do so. Approximately $£ 15$ million is spent weekly ( $£ 188$ million/quarter) on statins prescribed to an estimated 2.5 million people. The NSF has had less influence on a trend which was already increasing rapidly, but it has helped fund the $300 \%$ increase in expenditure.

The NSF was felt to be the key in achieving the government target of cutting death rates from CHD and stroke by $40 \%$ by 2010-Our Healthier Nation target. ${ }^{8}$ The age standardised death rates from CHD have in fact been falling since 1980 anyway and extrapolation of the graph to 2010 showed a $40 \%$ reduction before the introduction of the NSF.

\section{OUTSTANDING PROBLEMS}

On the negative side the primary angioplasty service for acute myocardial infarction stands out as an unmet need. This service remains in its infancy compared with the rest of Europe. Only 633 cases were registered as being primary PCI cases in 2003, and only $4.3 \%$ of all angioplasty procedures were for ST elevation infarcts. A limited pilot study of service models needed for primary PCI (funded by the Department of Health) has been started, but this is papering over the cracks of a service which at present is recognised as wholly inadequate for the country's needs.

Cardiac rehabilitation is another area where the NSF milestones have not been achieved. A survey by the Healthcare Commission ${ }^{9}$ showed that $63 \%$ of cardiac patients treated in English NHS trusts had not had any formal rehabilitation. There is chronic understaffing in this area, only one in four centres have purpose built facilities, and half do not hold their own budgets.

The inequalities of cardiac service provision in the UK were highlighted in a recent survey of the British Cardiac Society ${ }^{10}$ in which it is clear that devolution has disadvantaged Wales and Scotland and to a lesser extent Northern Ireland. Wales in particular has the lowest number of cardiologists/million of the population, the lowest number of catheter laboratories, and the lowest angioplasty rates in the UK. Wales now has its own NSF but they have not been blessed with the necessary financial investment. There is no doubt that exclusion from the English NSF and its organisational infrastructure has greatly disadvantaged these devolved nations.

\section{CONCLUSIONS}

The NSF for CHD has undoubtedly had a huge influence in improving cardiac services in England. We are only half way through a 10 year programme but much has been achieved. Its success can also be measured by the inequality and poorer service provision in the devolved countries without the NSF. There are still major gaps in some areas of the cardiac service, however. Priorities have been set to address these but there is still a long way to go.

\section{REFERENCES}

1 Department of Health. The National Service Framework for coronary heart disease. London: Department of Health, 2000.

2 Hampton JR. The National Service Framework for coronary heart disease: the emperor's new clothes. J Royal Coll Phys 2000;34:226-9.

3 Department of Health. Arrhythmias and sudden cardiac death (chapter 8). In: Coronary heart disease. London: Department of Health, 2005

4 Department of Health. Leading the way. Progress report 2005, http:// www.dh.gov.uk/PublicationsAndStatistics/Publications/ PublicationsPolicyAndGuidance.

5 Boyle R. The cost of national service frameworks. Hospital Medicine 2004;65:68-9.

6 Royal College of Physicians. Myocardial Infarction National Audit Project (MINAP) Fourth Public Report. London: Royal College of Physicians, 2005.

7 Graham JJ, Timmis A, Cooper J, et al. Impact of the National Service Framework for coronary heart disease on treatment and outcome of patients with acute coronary syndromes. Heart 2006;92:301-6.

8 Anon. Saving lives: our healthier nation, White paper, 1999

9 Healthcare Commission. Coronary heart disease: survey of patients, 2004 www.healthcarecommission.org.uk.

10 British Cardiac Society. National variations in the provision of cardiac services in the United Kingdom. Report of a working group of the British Cardiac Society. Br J Cardiol 2005;12:192-8. 